\title{
Survival and cause-specific mortality of female Rocky Mountain elk exposed to human activity
}

\author{
Stephen L. Webb • Matthew R. Dzialak • \\ John J. Wondzell · Seth M. Harju • \\ Larry D. Hayden-Wing · Jeffrey B. Winstead
}

Received: 24 June 2010/Accepted: 2 December 2010/Published online: 12 January 2011

(C) The Author(s) 2011. This article is published with open access at Springerlink.com

\begin{abstract}
Animal populations are becoming increasingly exposed to human activity as human populations expand and demand for energy resources (e.g., coal, oil and natural gas) increases. We initiated this study to document survival and cause-specific mortality patterns of female Rocky Mountain elk (Cervus elaphus) exposed to increasing levels of human activity. We fitted 184 females with VHF or GPS collars over 4 years and used the Kaplan-Meier survival estimator to calculate annual survival rates. We used multinomial logistic regression to assess differences in cause-specific mortality and generalized linear mixed models to determine how probability of survival was structured during hunting season; both analyses examined a suite of 5 covariates (i.e., age, year, extent of space use, cover, and human footprint) as potentially influencing cause-specific mortality and survival probability. Annual probability of survival averaged $0.8( \pm 0.02 \mathrm{SE})$ over 4 years but averaged $0.91( \pm 0.03 \mathrm{SE})$ when harvest mortality was excluded, which was the most significant source of mortality in most years $(\bar{x}=0.13 \pm 0.02 \mathrm{SE})$. We found no difference between cause-specific mortality sources relative to elk that survived during the hunting season $\left(\chi_{10}^{2}=5.79, P=0.832\right)$. The probability of a female surviving during hunting season was negatively influenced by age, year, extent of space use, cover, and human footprint. We found evidence that human activity may have influenced annual rates of natural survival (i.e., exclusive of hunting mortality) and probability of survival during the hunting season. We note that this study occurred largely on
\end{abstract}

S. L. Webb $(\bowtie) \cdot$ M. R. Dzialak · J. J. Wondzell ·

S. M. Harju - L. D. Hayden-Wing - J. B. Winstead

Hayden-Wing Associates, LLC, 2308 South 8th Street,

Laramie, WY 82070, USA

e-mail: stephen@haydenwing.com privately owned and managed residential and ranch land and focused on female elk; we acknowledge that survival rate and cause-specific patterns of mortality may vary as a function of land ownership (private vs. public), demographic status, and management and harvest practices. While temporal and spatial scales of 1 week may be sufficient to describe patterns of direct mortality during hunting season, broad temporal or spatial scale analyses may be needed to address natural mortality during other seasons.

Keywords Cervus elaphus - Colorado - Extent of space use $\cdot$ Forest cover $\cdot$ Human footprint $\cdot$ Mortality

\section{Introduction}

Survival rate has the potential to influence population size, recruitment, and sex ratios. Obtaining annual estimates of survival can be difficult (Bishop et al. 2005), but such rates are particularly important to collect in areas where largescale human activities are changing the face of the landscape. Populations of elk (Cervus elaphus) exposed to human activity may require monitoring to assess changes in survival rates, cause-specific mortality, and the factors that influence survival and mortality (i.e., limiting factors). Because of a dearth of information related to basic life history attributes of elk exposed to human activity, more studies are needed to make sound management decisions, especially under scenarios where multiple types of human activity (e.g., community development, energy development, infrastructure, hunting and other recreational activities) come together to influence population demographics. This scenario becomes increasingly important as more areas undergo development in habitats used by wildlife. 
In large species of cervids, adult female survival is one of the most influential population dynamics parameters based on elasticity and sensitivity analyses, thus resulting in significant contributions to population persistence and growth (Nelson and Peek 1982; Gaillard et al. 1998, 2000). Large cervids are considered as either assets for providing economic value from hunting and ecotourism or nuisances related to property damage (McShea et al. 1997), which has prompted much research on population dynamics of these species (Gaillard et al. 2000). However, there is a paucity of data related to the direct and indirect effects of human activity on population parameters such as survival. Survival patterns of female elk are of particular interest in Colorado, USA, because of their economic importance, influence on population persistence and growth, and spatial associations with human activity and ongoing development of underground energy reserves (e.g., coal-bed natural gas).

Much research has focused on the effects of roads on elk survival (Cole et al. 1997; Hayes et al. 2002; McCorquodale et al. 2003). Few studies have incorporated other sources of human related activity (e.g., housing, industrial and energy development, ranching) on the probability of survival in elk. We initiated this study to document survival and cause-specific mortality patterns of female Rocky Mountain elk in relation to cumulative human activity, to which we refer collectively as the human footprint. This study was part of a larger research project examining the influence of development for energy on resource selection, site fidelity and movement of female elk. The objectives of this study were to: (1) document annual survival and causespecific mortality patterns of female Rocky Mountain elk; and (2) determine what factors influenced susceptibility to harvest and probability of survival during hunting season.

\section{Materials and methods}

\section{Study site}

The study area was located in the Raton Basin in Costilla, Las Animas and Huerfano counties of south-central Colorado, and Colfax and Taos counties in northern New Mexico (Fig. 1). Land ownership was predominately private, which comprised $\sim 89 \%$ of the area (Vitt 2007). Ranching, hunting, energy development, and residential home development were the predominant land use practices. The core of the study area $\left(1,370 \mathrm{~km}^{2}\right)$ encompassed historic bituminous coal mining during 1873-1995 and coal-bed methane gas development since 1982 (Hemborg 1998). As of 2009, the core gas field contained 2,421 well pads (1.77 well pads $\left./ \mathrm{km}^{2}\right)$ and 2,933 wells (2.14 wells $/ \mathrm{km}^{2}$ ); some well pads had multiple wells on each site. Areas adjacent to, but outside, the core gas field are referred to herein as "outside the gas field." On an annual basis, 45.8\% ( $n=65)$ of elk fitted with GPS collars used areas inside the gas field, $17.6 \%(n=25)$ used areas outside the gas field, and $36.6 \%(n=52)$ used both areas. Human modification of the landscape inside the core gas field included: well pads and associated structures, communities, residences, buildings, industries, ranching activities, roads, railroads, and pipelines. Human modification to the landscape outside the gas field included the aforementioned development except for well pads and associated structures. Therefore, elk inside the core gas field were exposed to human activities and infrastructure associated with natural gas development, whereas elk outside the core gas field were only exposed to human activity exclusive of natural gas development. Although roads were present in both areas, total road density was 2.2 times greater inside the core gas field $(2.4$ $\mathrm{km} / \mathrm{km}^{2}$ ) compared to outside the gas field $\left(1.1 \mathrm{~km} / \mathrm{km}^{2}\right)$. Average sizes (ha) of disturbances were 1.5 ( $\pm 0.15 \mathrm{SE}$ ) for ranching, $3.2( \pm 0.73)$ for industrial development, 17.2 ( \pm 13.63$)$ for community, $0.3( \pm 0.02)$ for residences, and 0.5 $( \pm 0.01)$ for well pads. The ratio of unmodified $\left(\mathrm{km}^{2}\right)$ to modified areas $\left(\mathrm{km}^{2}\right)$ inside the core gas field was $32: 1$, and outside the gas field it was 45:1. The population of elk on our study area received less hunting pressure than herds that occupied predominantly public land due to restricted hunter access. Potential predators of elk on the study area included black bears (Ursus americanus), mountain lions (Puma concolor), and coyotes (Canis latrans).

Topography ranges from rolling ridges and valleys to steep alpine slopes and cliffs (Vitt 2007) with elevations ranging from 1,800 to $4,300 \mathrm{~m}$. Mean annual precipitation ranges from $15 \mathrm{~cm}$ at lower elevations to $51 \mathrm{~cm}$ at higher elevations (Vitt 2007). We obtained site-specific temperature data from 7 weather stations located across the study area at elevations ranging from 1,983 to $2,841 \mathrm{~m}$. At the highest elevation weather station, minimum and maximum January and July temperatures were -26.3 and 12.4, and 3.2 and $26.4^{\circ} \mathrm{C}$, respectively. At the lowest elevation weather station, minimum and maximum January and July temperatures were -25.2 and 20.9 , and 7.1 and $33.8^{\circ} \mathrm{C}$, respectively.

\section{Capture and handling}

We captured female elk using a helicopter and either a dartgun or net-gun annually during February and March 2006-2009. Animals captured using the net-gun were manually restrained (i.e., not chemically immobilized) with hobbles and fitted with blindfolds to reduce stress. Darted elk were anesthesized using either carfentanil or a synthetic narcotic thiafentanil (A-3080). Sedated elk were also restrained with hobbles and fitted with blindfolds. Naltrexone was used as an antagonist to both carfentanil and thiafentanil. We estimated the ages of the elk using tooth erruption, replacement and wear techniques (Quimby and Gaab 1957). All elk were fitted with 
Fig. 1 Area used by female Rocky Mountain elk (Cervus elaphus) from 2006 to 2010 in the Raton Basin located in Costilla, Las Animas and Huerfano counties of southcentral Colorado, and Colfax and Taos counties in northern New Mexico. Gray shaded area on county map represents extent of space use by elk fitted with GPS collars

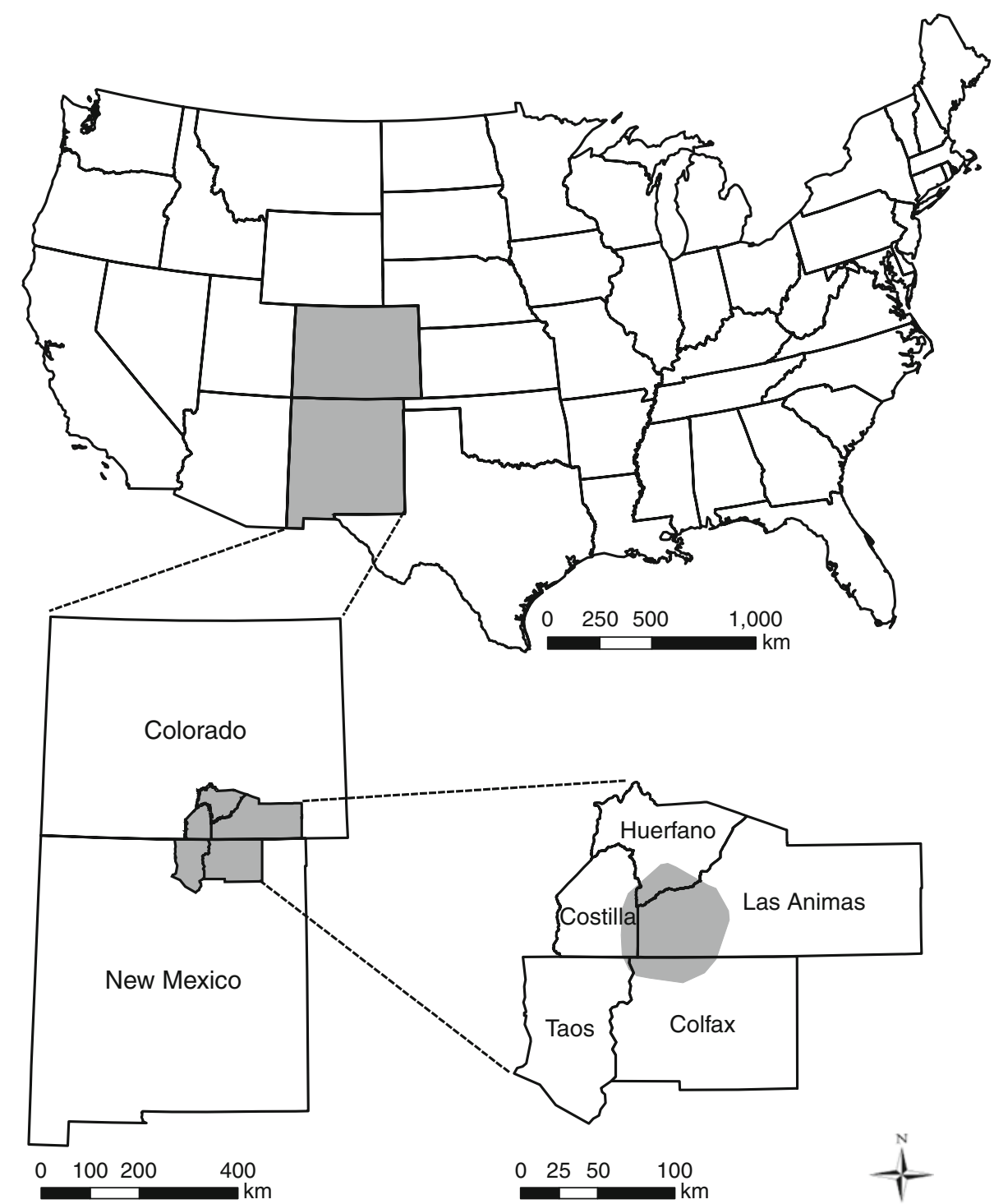

either a VHF (MOD-500 or MOD-501; Telonics, Mesa, AZ, USA) or GPS collar (TGW-3590; Telonics) and released at site of capture. We captured 184 individual elk over 4 years; 25, 32, 71 and 56 during 2006, 2007, 2008 and 2009, respectively. Eight elk were recaptured in 2007, 9 in 2008 and 5 in 2009. Ages of females at time of capture ranged from 1 to 12 years $(\bar{x}=5.6 \pm 0.2 \mathrm{SE}$; median $=5)$. Animal capture and handling protocols were approved by the Colorado Division of Wildlife (Permit nos. 06TR1083, 07TR1083, 08TR1083 and 09TR1083A001).

Data collection

\section{Survival}

We conducted aerial radio-tracking of both VHF and GPS collars every 2-4 weeks via fixed-wing aircraft to determine whether a mortality had occurred. Mortality sensors were programmed at the factory to be triggered after the collar was stationary for $8 \mathrm{~h}$. When a mortality signal was detected, a ground crew located the carcass and attempted to determine the cause of death. For elk fitted with VHF collars, we used the midpoint between the last date known alive and the first date of detecting the mortality as the date of mortality for survival analyses. For elk fitted with GPS collars, we used GPS location estimates to pinpoint the date of mortality by examining date, time and distance between locations.

\section{Landscape covariates}

We modeled the proportion of security cover and human footprint (i.e., area of human activity) within areas used by elk to determine whether these factors influenced 
probability of survival during hunting season. We determined temporal changes in the human footprint and security cover from annual high-resolution aerial photography. The human footprint and security cover were year-specific, meaning that we updated current, on-the-ground human activities and available security cover as annual aerial photography became available, and attributed proportion of human footprint and cover known to be present at the time the area was used by the elk (see below). We delineated the following areal surface features: vegetation cover and human activities, which included natural gas well pads and ancillary facilities, residences, buildings, industries, and ranching activities. We also included linear features such as roads, railroads and pipelines into our human footprint layer. Because these linear features had an area associated with them, we measured the width $(w)$ for a subsample of each feature. Areal and linear features were interpreted, digitized, and attributed based on annual aerial photography (2006-2009) and ground verification to confirm values of attributes. We used heads-up digitizing of all visible linear and areal surface features within our study area and performed all spatial analyses using $\operatorname{ArcGIS}^{\circledR} 9.3$ software (ESRI, Redlands, CA, USA).

Roads were divided into 5 classes (1-5): paved roads such as interstates (1); paved state, county and farm roads (2); improved, but unpaved, access roads to well pads or residencies consisting of gravel or crushed stone (3); unimproved roads such as dirt (4); and unimproved transportation routes such as pipeline or power line rights-ofway (5). We randomly sampled 20 replicates of each road class (total samples $=100$ ) and railroads $(n=20)$ to determine average width of disturbance associated with each. Pipelines were included as Class 5 roads because pipeline rights-of-way were unimproved and also used as transportation corridors. Buffers were equal to $1 / 2\left(\bar{x}_{w}\right)$. We set our buffer distances by rounding to the nearest $0.1 \mathrm{~m}$. Buffer distances were 5.2, 4.0, 2.6, 1.8, 1.7 and $2.1 \mathrm{~m}$ for Classes 1, 2, 3, 4, and 5, respectively. All disturbance features were merged into a single feature layer using the Union Overlay Method in ArcGIS ${ }^{\circledR}$ 9.3.

We developed a vegetation cover type map using high resolution $(0.3 \mathrm{~m})$ true-color and color-infrared (CIR) aerial photography and Feature Analyst ${ }^{\circledR} 4.2$ (FA; Visual Learning Systems, Missoula, MT, USA) for ArcGIS ${ }^{\circledR} 9.3$ (Visual Learning Systems 2008). We conducted a supervised classification using delineated polygons of known vegetation cover type for use with object-based feature extraction algorithms. The true-color and CIR bands were combined using FA, which resulted in 4 spectral bands (i.e., red, green, blue and near-infrared); the green spectral band was used to develop a texture band. Digital elevation models were used to develop an elevation band, which finally resulted in 6 bands (i.e., 4 spectral bands, 1 texture band and 1 elevation band). Last, we varied resolution/ pixel classifier pattern and size combinations based on vegetation type. Prior to running classifiers, vegetation cover types that occurred over extensive areas (i.e., dense forest, open forest, oak-dominated shrubland, alpine and grassland) were resampled to $3-\mathrm{m}$ resolution and vegetation cover types that were more restricted or linear (i.e., riparian) were resampled to $1.5-\mathrm{m}$ resolution. We used the Manhattan classifier pattern and a width of 7 pixels to classify extensive vegetation types. The Bull's Eye 2 classifier using 15 pixels was used to classify more restricted vegetation types. For these analyses, we reclassified the 6 vegetation classes into either cover or noncover habitat; all vegetation classes except alpine and grassland habitats were classified as cover.

\section{Data analysis}

\section{Annual and seasonal survival}

We calculated Kaplan-Meier survival estimates (Kaplan and Meier 1958) modified for a staggered-entry design (Pollock et al. 1989) over 4 years to determine annual survival (year 1: 16 March 2006-28 February 2007; year 2: 1 March 2007-28 February 2008; year 3: 1 March 2008-28 February 2009; year 4: 1 March 2009-28 February 2010). We also were interested in calculating annual causespecific mortality for the following sources: capture, harvest, natural or unknown and vehicle. We also calculated annual survival considering all sources of mortality except harvest (i.e., all harvest mortalities were censored). To determine cause-specific mortality we censored all sources except the cause of interest (Pollock et al. 1989). For example, when calculating non-harvest mortality, we censored all harvest mortalities, and to determine survival considering only harvest mortality, we censored all nonharvest mortalities. We analyzed all years separately because human activity and associated modification to the landscape increased with time (e.g., development of roads, gas wells and residential structures). Anthropogenic disturbance associated with infrastructure increased $10.6 \%$ from year 1 (3,893.9 ha) to year 2 (4,308.4 ha), 2.9\% from year 2 to year $3(4,432.9$ ha), and remained virtually unchanged from year 3 to year 4 .

We further characterized cause-specific mortality by season to document patterns in mortality relative to time of year. Results of seasonal survival summaries provided insights into periods within which most mortality occurred. Seasons were based on a combination of biological factors, environmental variables and hunting seasons and were defined as hunting, winter, and reproduction. Hunting seasons for female elk in Colorado began in late August [earliest $=25$ th (2007); latest $=30$ th (2008) $]$ and ended 
31 January. Thus, we defined the hunting season from 1 September to 31 January the following year. Winter was a period from February to April and the reproductive season of females was defined as May to August, which included parturition and lactation.

\section{Conceptual framework}

We examined the influence of extent of space use (ha) by elk and the proportion of the human footprint and security cover within these areas on cause-specific mortality and probability of survival during hunting season at a temporal scale of 1 week. Most mortality occurred during the hunting season (Table 1); therefore, areas used by elk and features within these areas may influence elk vulnerability to mortality. During the hunting season, we included all sources of mortality observed during the hunting season (i.e., harvest, unknown or natural) into our analyses except vehicle collisions due to limited sample size $(n=2)$. We chose a 1-week temporal window during the hunting season because most mortalities were due to harvest (Table 1), an event that likely reflected the choices made by both elk and hunters at the time of harvest or immediately preceding harvest. Energy companies previously agreed to limit activities during crepuscular hours $(\sim 0600-0900$ and 1500-1800 hours) when hunters were present, at the request of landowners.

To describe areas used by elk the week preceding the mortality event, we calculated a $100 \%$ minimum convex polygon (MCP) around all points during a 7-day period using Home Range Tools (HRT) for ArcGIS ${ }^{\circledR}$ (Rodgers et al. 2005). For comparison, we calculated extent of space use for elk that survived the hunting season, also during a 7-day period that was randomly selected. Throughout, extent of space use refers to the $100 \% \mathrm{MCP}$ around all locations during a 7-day period. We randomly chose a 1-week period for each individual elk that survived during the hunting season to describe features of the landscape used by surviving elk. We used a random number

Table 1 Cause-specific mortalities (i.e., number) of female Rocky Mountain elk (Cervus elaphus) during hunting (September-January), winter (February-April) and reproduction (May-August) from March 2006 to March 2010 in the Raton Basin of south-central Colorado

\begin{tabular}{llllr}
\hline Mortality source & \multicolumn{2}{l}{ Season } & Total \\
\cline { 2 - 4 } & Hunting & Winter & Reproduction & \\
\hline Harvest & 26 & 0 & 0 & 26 \\
Vehicle & 2 & 0 & 0 & 2 \\
Unknown & 5 & 2 & 2 & 9 \\
Capture & 0 & 2 & 0 & 2 \\
Total & 33 & 4 & 2 & 39 \\
\hline
\end{tabular}

generator, without replacement, to assign week to elk. During years when more elk were tracked than the number of weeks in the hunting season, we ran the random number generator the required number of times until all elk were assigned a week at random. This method reduced the number of elk assigned to the same week and allowed us to sample areas used by surviving elk over the entire hunting season. We used the MCP method for the 1-week interval because it would describe the entire area covered by the elk. Because of the short time interval, MCP would not be as affected by distributional shifts in areas of use by elk.

We classified the amount of human activity (i.e., human footprint) and cover (see "Landscape covariates" above) within each individual's area (i.e., extent of space use) and report human footprint and cover as a proportion of the area associated with space use. For example, proportion of human footprint was 0.05 , which was calculated by dividing the human footprint area (i.e., $25 \mathrm{ha}$ ) by total extent of space use (i.e., $500 \mathrm{ha}$ ). We also included age and year into models as explanatory variables.

We predicted elk would have reduced survival, or greater mortality: (1) when using less cover, greater human footprint, and larger spatial extents; (2) as age increased; and (3) as the study progressed due to increasing human activity through time. Specifically, (1) reduced cover would offer less protection from predators (i.e., natural or human) and human activities; (2) a larger human footprint may increase stress because of increased or more widespread human activity (Millspaugh et al. 2001), energy expenditure to avoid human activity (Parker et al. 1984), and vulnerability to direct human intrusion; (3) larger extents of space use would likely be an artifact of increased movement, which may result in increased energy expenditure or direct contact with mortality sources (e.g., vehicles, humans, predators); (4) increasing age may reduce survival due to senescence (Gaillard et al. 1998, 2000); and (5) increases in human activity through time, irrespective of the amount within home ranges, could decrease probability of survival.

\section{Likelihood of cause-specific mortality}

To assess how covariates influenced cause-specific mortality of female elk during the hunting season, with reference to elk that survived, we used multinomial logistic regression (MLR; PROC LOGISTIC), a framework similar to Bishop et al. (2005). Cause-specific mortality was placed into 2 groups: harvest and unknown or natural causes. We used MLR to examine how age, year, extent of space use, and proportion of cover and human footprint within areas used 1 week prior to the mortality event influenced likelihood of succumbing to mortality due to different causes. We used a generalized logit-link function (i.e., glogit) to 
model the nominal response variable with 3 levels $(0$, survived; 1 , mortality due to harvest; 2 , mortality due to unknown or natural causes). The group of elk that survived was used as the reference group.

\section{Probability of survival}

In addition to investigating factors affecting cause-specific mortality, we used generalized linear mixed models (GLMM; PROC GLIMMIX) to determine the influence of age, year, extent of space use, and proportion of human footprint and cover on the probability of survival during the hunting season relative to non-specific causes of mortality (i.e., all sources of mortality pooled). Fate was analyzed as a binary response variable (1, survived; 0 , died); both harvest and unknown or natural mortalities were pooled for analysis. We included elk identification as a random effect to account for repeated entries of elk that survived multiple years. For our GLMM, we used a binary distribution and a logit-link function. All analyses were conducted using SAS $^{\circledR} 9.2$ (SAS Institute, Cary, NC, USA).

\section{Results}

We documented 39 total mortalities from all sources over the course of the study (Table 1). Most mortalities were concentrated during the hunting season $(84.6 \% ; 33$ of 39$)$ followed by winter $(n=4)$ and reproduction $(n=2$; Table 1). Twenty-six elk (66.7\%) died due to harvest, which was the most common source of mortality (Table 1). Two elk died from capture, 2 from vehicles, and 9 from unknown or natural causes (Table 1). Of the elk-vehicle collisions, 1 elk was struck by a train and the other by a car.
Annual survival, accounting for all sources of mortality, ranged from 0.76 to 0.85 over 4 years $(\bar{x}=0.80 \pm 0.02 \mathrm{SE}$; Table 2). Harvest mortality was the most common source of mortality in most years (range $=0.08-0.16 ; \bar{x}=0.13 \pm$ $0.02 \mathrm{SE} ;$ Table 2). After excluding harvest mortality, annual survival ranged from 0.83 to $0.95(\bar{x}=0.91 \pm 0.03 \mathrm{SE})$. Unknown or natural mortality accounted for $0.05-0.07$ of the total mortalities over 4 years $(\bar{x}=0.06 \pm 0.01 \mathrm{SE}$; Table 2). Average annual rates of survival in this study, including all sources of mortality $(\bar{x}=0.80)$, were within the range of other populations of elk $(\bar{x}=0.84)$ and hunted populations in Colorado $(\bar{x}=0.76)$. Average annual rate of survival in this study, excluding harvest mortality, was 0.91 . Annual rate of survival, excluding harvest mortality, documented as part of previous research in Colorado ranged from 0.92 to 1.0 annually (Table 3 ).

Mortality may have been structured differently between specific causes (i.e., harvest and unknown or natural) in relation to covariates; therefore, we used MLR models to assess differences between cause-specific mortality groups with reference to the group of elk that survived. We found no statistical differences among the 3 groups relative to age $\left(\chi_{2}^{2}=3.19, \quad P=0.203\right)$, year $\left(\chi_{2}^{2}=0.49, \quad P=0.781\right)$, extent of space use $\left(\chi_{2}^{2}=0.63, P=0.731\right)$, proportion of human footprint $\left(\chi_{2}^{2}=0.72, P=0.698\right)$ or proportion of $\operatorname{cover}\left(\chi_{2}^{2}=0.37, P=0.833\right)$.

Given that there was no difference between harvest and unknown or natural mortalities relative to model covariates, we pooled mortality into a single group and assessed how age, year, extent of space use, and proportion of human footprint and cover within these areas were structured between elk that survived and those that died. We found probability of survival was not influenced statistically by age $\left(F_{1,12}=2.23, P=0.161\right)$, year $\left(F_{1,12}=0.48\right.$, $P=0.503)$, extent of space use $\left(F_{1,12}=0.02, P=0.901\right)$,

Table 2 Probability of annual survival and cause-specific mortality for female Rocky Mountain elk (Cervus elaphus) in south-central Colorado from March 2006 to March 2010

\begin{tabular}{|c|c|c|c|c|c|c|c|c|}
\hline & \multicolumn{2}{|l|}{ Year 1} & \multicolumn{2}{|l|}{ Year 2} & \multicolumn{2}{|l|}{ Year 3} & \multicolumn{2}{|l|}{ Year 4} \\
\hline & Mean (SE) & $95 \% \mathrm{CI}$ & Mean (SE) & $95 \% \mathrm{CI}$ & Mean (SE) & $95 \% \mathrm{CI}$ & Mean (SE) & $95 \% \mathrm{CI}$ \\
\hline Survival $^{\mathrm{a}}$ & $0.76(0.09)$ & $0.59,0.93$ & $0.85(0.06)$ & $0.74,0.96$ & $0.79(0.05)$ & $0.69,0.89$ & $0.80(0.05)$ & $0.70,0.91$ \\
\hline \multicolumn{9}{|l|}{ Mortality $^{\mathrm{b}}$} \\
\hline Harvest & 0.08 & & 0.11 & & 0.16 & & 0.16 & \\
\hline Vehicle & 0.09 & & $--^{c}$ & & $-^{c}$ & & $--^{c}$ & \\
\hline Unknown & 0.05 & & 0.05 & & 0.05 & & 0.07 & \\
\hline Capture & 0.05 & & $-^{\mathrm{c}}$ & & 0.02 & & $-{ }^{c}$ & \\
\hline All sources except harvest & 0.17 & & $0.05^{\mathrm{d}}$ & & 0.07 & & $0.07^{\mathrm{d}}$ & \\
\hline
\end{tabular}

a Survival was calculated using the Kaplan-Meier survival estimator modified for a staggered-entry design

${ }^{b}$ Cause-specific mortality was calculated by censoring all other sources of mortality, except the cause of interest

c Source of mortality not observed

d Same probability as unknown source 
Table 3 Summary of survival estimates for female elk (Cervus elaphus) across western Canada and United States from 1968 to 2006 in areas without development for energy resources

\begin{tabular}{|c|c|c|c|}
\hline Study area & Survival $( \pm \mathrm{SE})$ & Method & References \\
\hline Canada $^{\mathrm{a}}$ & $0.89(0.06)$ & VHF collars & Hebblewhite et al. (2005) \\
\hline \multirow[t]{3}{*}{ Arizona } & $0.9^{\mathrm{b}}(<0.01)$ & VHF collars & Ballard et al. (2000) \\
\hline & $0.97^{\mathrm{c}}(<0.01)$ & & \\
\hline & $0.94^{\mathrm{d}}(0.01)$ & & \\
\hline \multirow[t]{7}{*}{ Colorado } & $0.91\left(0.01^{\mathrm{e}}\right)$ & VHF collars & Lubow et al. (2002) \\
\hline & $0.76^{\mathrm{f}}(0.06)$ & VHF collars & Freddy $(1997,2000,2003)$ \\
\hline & $0.96(0.04)^{\mathrm{g}}$ & VHF collars & Freddy (1997) \\
\hline & $0.92-1.0^{\mathrm{g}, \mathrm{h}}$ & VHF collars & Freddy (2000) \\
\hline & $0.97(0.05)^{\mathrm{g}}$ & VHF collars & Freddy (2003) \\
\hline & $0.8^{\mathrm{i}}(0.02)$ & GPS collars & This study \\
\hline & $0.91^{\mathrm{j}}(0.03)$ & GPS collars & This study \\
\hline \multirow[t]{2}{*}{ Idaho $^{\mathrm{k}}$} & $0.89(0.09)$ & VHF collars & Unsworth et al. (1993) \\
\hline & $0.88^{1}$ & VHF collars & Leptich and Zager (1991) \\
\hline Montana & $0.83\left(0.03^{\mathrm{e}}\right)$ & VHF collars & Kunkel and Pletscher (1999) \\
\hline Oregon & $0.9\left(0.02^{\mathrm{m}}\right)$ & VHF collars & Stussy et al. (1994) \\
\hline \multirow[t]{3}{*}{ Utah } & $0.64\left(0.05^{\mathrm{e}}\right)$ & Tag recovery & Kimball and Wolfe (1974) \\
\hline & $0.78^{\mathrm{n}}$ & Age structure $^{\circ}$ & Kimball and Wolfe (1979) \\
\hline & $0.74\left(0.04^{\mathrm{e}}\right)$ & Tag recovery & \\
\hline \multirow[t]{3}{*}{ Washington } & $0.93\left(0.03^{\mathrm{m}}\right)$ & Counts $^{p}$ & Eberhardt et al. (1996) \\
\hline & $0.83\left(0.05^{\mathrm{e}}\right)$ & VHF collars & McCorquodale et al. (2003) \\
\hline & $0.89(0.06)$ & VHF transmitters ${ }^{\mathrm{q}}$ & Michaelis et al. (2005) \\
\hline \multirow[t]{5}{*}{ Wyoming } & $0.65\left(0.09^{\mathrm{m}}\right)$ & Tag recovery & Sauer and Boyce (1983) \\
\hline & $0.97^{\mathrm{r}}(0.02)$ & VHF collars & Lubow and Smith (2004) \\
\hline & $0.74^{\mathrm{s}}$ & & Straley (1968) \\
\hline & $0.83^{\mathrm{t}}\left(0.03^{\mathrm{e}}\right)$ & VHF and GPS collars & Evans et al. (2006) \\
\hline & $0.8^{\mathrm{u}}\left(0.04^{\mathrm{e}}\right)$ & & \\
\hline
\end{tabular}

Results from this study were added as a reference

${ }^{\text {a }}$ Wolves made limited use of area due to human activity

${ }^{\mathrm{b}}$ Hunted on state property

${ }^{c}$ Unhunted on state property

${ }^{\mathrm{d}}$ Moderately hunted on reservation

e Derived from confidence intervals

${ }^{f}$ Average of annual survival estimates, including harvest mortality, for the 3 studies

g Natural survival, excluding harvest mortality, calculated using the binomial estimator

h Only range reported

i Average survival of years 1-4 including all sources of mortality

j Average survival of years 1-4 excluding harvest mortality

${ }^{\mathrm{k}}$ Limited hunting by native Americans

${ }^{1}$ SE not reported

${ }^{m}$ Derived from annual survival rates

${ }^{n}$ SE not reported for estimate of unbiased survival rate

${ }^{\circ}$ Survival rate estimated from age structure of composite sample of harvested animals

${ }^{\mathrm{p}}$ Approximate survival rates were derived by dividing the current number of post-calving adults by adults plus yearlings from the previous year

q VHF transmitters incorporated into rumen (79\%) and neck collars (21\%)

${ }^{\mathrm{r}}$ Annual natural survival excluding harvest

${ }^{s}$ Reported in Sauer and Boyce (1983)

${ }^{\mathrm{t}}$ Survival of females aged $1-15$ years

u Survival of all females 
Fig. 2 Extent of space use (ha; a), proportion of human footprint (b) and cover (c) within 1-week spatial extents used by female elk (Cervus elaphus) that survived or succumbed to mortality during the hunting season (SeptemberJanuary) in south-central Colorado, 2006-2010. Each dot represents an individual elk within respective group. Group means and $95 \%$ CI of each variable for alive $(+)$ and dead $(X)$ elk are displayed to the right of the respective group of individuals
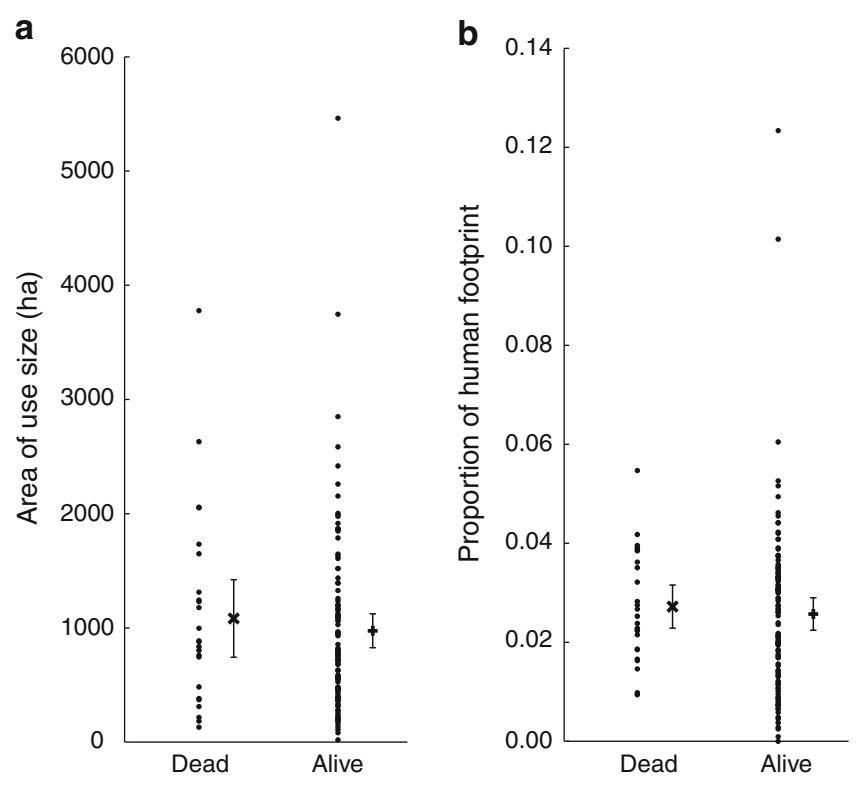

proportion of human footprint $\left(F_{1,12}=0.23, P=0.638\right)$ or proportion of cover $\left(F_{1,12}=0.19, P=0.671\right)$ because group means were similar between surviving and dying elk (Fig. 2). Statistical non-significance notwithstanding, we note that the direction of the sign on parameter estimates was consistent with expectation given the published literature (see below), except for the proportion of cover. Survival probability decreased with increasing age $\left(\beta_{\text {age }}=\right.$ $-0.17 \pm 0.11 \mathrm{SE})$, year $\left(\beta_{\text {year }}=-0.17 \pm 0.24 \mathrm{SE}\right)$, human footprint $\left(\beta_{\text {dist }}=-6.57 \pm 13.63 \mathrm{SE}\right)$ and extent of space use $\left(\beta_{\text {area }}=-0.0001 \pm 0.0003\right.$ SE). However, probability of survival decreased with increasing cover $\left(\beta_{\text {cover }}=-0.89 \pm 2.05 \mathrm{SE}\right)$.

\section{Discussion}

Strong associations between survival parameters (annual rate of survival and probability of survival during hunting season) and covariates were not apparent in this human modified landscape. While it is clear that elk have adapted, to some extent, to human activity in this area (sensu Thompson and Henderson 1998), we offer several observations based on biological trends in the data that might inform management of elk populations and human activity in multiple-use landscapes. First, annual rate of survival documented herein, including harvest, was within the range of previously reported values (0.64-1.0; Table 3). However, our observed survival rate was slightly lower $(\bar{x}=0.80)$ than the average rate of survival $(\bar{x}=0.84)$ calculated across 19 other populations of elk where human activity was less intense or widespread (Table 3). Second, while annual rate of survival exclusive of hunting mortality

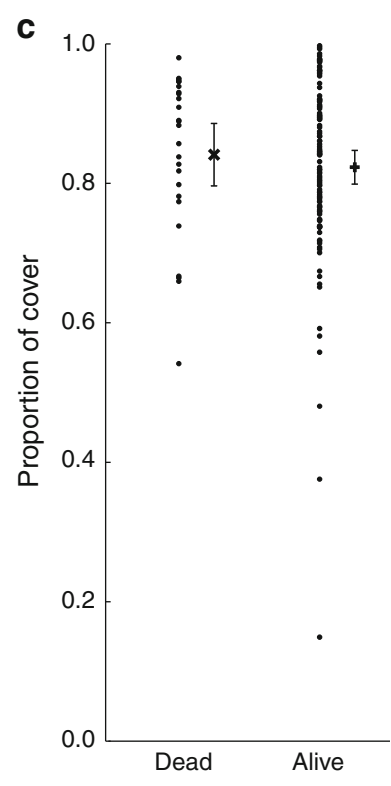

was high in this study $(\bar{x}=0.91)$, Freddy $(1997,2000$, 2003) documented annual natural (excluding harvest) rates of survival that ranged from 0.92 to 1.0 in other portions of Colorado where human activity was comparably less, although $100 \%$ annual survival appears exceptionally high (Table 3). In many large herbivores, adult survival has been considered more important in determining population growth rates than other vital rates (Nelson and Peek 1982; Gaillard et al. 1998). Last, we did a post-hoc analysis (i.e., binary logistic regression) to determine whether the location of an elk's home range relative to the core gas field influenced probability of survival. We found elk using the core gas field $\left(\beta_{\text {in }}=-0.91 \pm 0.73 \mathrm{SE}\right)$, or any area associated with it $\left(\beta_{\text {both }}=-0.04 \pm 1.0 \mathrm{SE}\right)$, had a lower probability of survival relative to elk using areas outside the gas field, albeit not with statistical significance $(P>0.05)$. In this same post-hoc analysis, cover positively influenced probability of survival $\left(\beta_{\text {cover }}=0.60 \pm 2.31\right.$ $\mathrm{SE}$ ), which may indicate that cover mitigates some of the effects of increased human activity (see below). While a statistical link between human activity and survival was not established herein, these observations underscore a consistent biological pattern of slightly reduced survival among adult females where human activity is widespread, and suggest that ongoing monitoring of the population would be warranted and prudent.

Few studies have examined the influence of human activity on fitness measures (e.g., survival) of large ungulates. For this reason, we interpreted the direction and magnitude of the relationships for guiding researchers when designing future studies. Although probability of survival was not influenced by the proportion of human footprint based on statistical significance, it was also important to 
consider the direction of the relationship between survival and human activity from a biological perspective (Guthery 2008). We acknowledge that very different patterns of survival may have been observed on predominately public land, at different temporal and spatial scales and on different segments of the population (i.e., varying age and sex). We found a trend for probability of survival to decrease as human footprint increased within areas used by elk 1 week prior to mortality. Similar patterns of survival were observed in relation to roads; survival decreased as density of roads increased (Leptich and Zager 1991; Unsworth et al. 1993; Cole et al. 1997; Hayes et al. 2002; Raedeke et al. 2002; McCorquodale et al. 2003). It is likely that the composite human footprint variable we developed captured the effects of roads because roads accounted for most of the human footprint within areas used by elk.

The hunting season is a particularly vulnerable time for elk because harvest is the major source of mortality of elk in hunted populations (Leptich and Zager 1991; Unsworth et al. 1993; Ballard et al. 2000; Raedeke et al. 2002; McCorquodale et al. 2003). Road networks, particularly on public land, can influence hunter behavior (Lyon and Burcham 1998) and disturbance to elk. Lyon and Burcham (1998) observed most hunters spend one-quarter of their time on roads and the rest within an average $267 \mathrm{~m}$ of a road. Our study area contained a large network of roads resulting in $\sim 95 \%$ of the area being within $400 \mathrm{~m}$ of the nearest road (S.L. Webb, unpublished data). If this network of roads was present on public land then hunters would have access to most areas via road access, which could result in increased disturbance or harvest of elk above what we observed on predominantly private land. Expansive road networks may also increase illegal activity such as poaching. In Oregon, for example, high road densities resulted in increased poaching of elk (Stussy et al. 1994). Large road networks may promote illegal harvest because poachers are in close proximity to roads where they can quickly and easily harvest an elk and get out of the forest via an extensive road network without being caught. However, illegal harvest may not be as prominent on our study area, even with relatively dense road networks, due to private land ownership status where most access is limited by secure gates. In our study area, differences among landowners in the timing, duration, type, and intensity of hunting (i.e., some landowners hunt lightly, some hunt intensively, and some establish refugia where hunting is non-existent) complicates a mechanistic assessment of the relationship among infrastructure, human activity, and harvest mortality.

Post-hoc analyses replaced the continuous measure of human footprint with a classification variable describing the location of an elk's home range relative to natural gas development and supported a priori predictions that probability of survival increased as the proportion of cover increased within the spatial extents used by elk during hunting season. Based on this association, security cover may mitigate some of the influence human activity has on animal behavior (Edge et al. 1985) because animals are able to retreat to safe environments. Using areas with greater cover may reduce the potential for contacts with humans or direct mortality events (e.g., harvest), which could confer advantages to individuals by increasing survival and reproduction (Garshelis 2000). Within the study area, humans may constitute a greater risk of predation or disturbance than naturally occurring predators. Numerous studies have found that security cover is important for reducing predation risk (Wolff and Van Horn 2003; Creel et al. 2005; Fortin et al. 2005; Winnie and Creel 2007). Therefore, the finding of an association between cover and probability of survival corroborates previous work on predation risk theory and the use of security cover.

By assessing both direct and indirect causes of mortality, we were able to identify potentially meaningful biological trends in the association between survival in female elk and industrial development. The observed biological trend between decreasing survival with increasing human footprints, or use of areas within or nearer to the gas field, warrants further investigation to address the wide range of potentially complicating factors at multiple temporal and spatial scales and across varying demographic groups and landownership status. For instance, using temporal and spatial scales of 1 week may be sufficient to describe direct mortality events such as harvest, but may be less useful for detecting broad-scale influences on fitness measures (McLoughlin et al. 2005, 2006), particularly if resources and landscape features (e.g., human footprints) function through physiological pathways. Decreased survival due to increased human activity may be an important management implication to consider, especially in harvested populations living in variable environments and on multiple-use landscapes. Just as important, cover may mitigate some of the impacts human activities have on elk (Edge et al. 1985), so maintaining large blocks of security cover may be a viable management practice. Lastly, populations of animals living in disturbed environments may need to be monitored more intensively to determine if, and when, human activity influences population demographics or dynamics.

Acknowledgments We thank: Pioneer Natural Resources Company for funding our research; R. Osborn for project assistance; J. Mudd for expertise with Feature Analyst; the Colorado Division of Wildlife for guidance; and landowners in the Raton Basin for participation and access to land. M. Cobben, C. Hedley and several anonymous reviewers improved earlier drafts of this manuscript. 
Open Access This article is distributed under the terms of the Creative Commons Attribution Noncommercial License which permits any noncommercial use, distribution, and reproduction in any medium, provided the original author(s) and source are credited.

\section{References}

Ballard WB, Whitlaw HA, Wakeling BF, Brown RL, deVos JC Jr, Wallace MC (2000) Survival of female elk in northern Arizona. J Wildl Manage 64:500-504

Bishop CJ, Unsworth JW, Garton EO (2005) Mule deer survival among adjacent populations in southwest Idaho. J Wildl Manage 69:311-321

Cole EK, Pope MD, Anthony RG (1997) Effects of road management on movement and survival of Roosevelt elk. J Wildl Manage 61:1115-1126

Creel S, Winnie J Jr, Maxwell B, Hamlin K, Creel M (2005) Elk alter habitat selection as an antipredator response to wolves. Ecology 86:3387-3397

Eberhardt LE, Eberhardt LL, Tiller BL, Cadwell LL (1996) Growth of an isolated elk population. J Wildl Manage 60:369-373

Edge WD, Marcum CL, Olson SL (1985) Effects of logging activities on home-range fidelity of elk. J Wildl Manage 49:741-744

Evans SB, White PJ, Sargeant GA (2006) Survival of adult female elk in Yellowstone following wolf restoration. J Wildl Manage 70:1372-1378

Fortin D, Beyer HL, Boyce MS, Smith DW, Duchesne T, Mao JS (2005) Wolves influence elk movements: behavior shapes a trophic cascade in Yellowstone National Park. Ecology 86:1320-1330

Freddy DJ (1997) Estimating survival rates of elk and developing techniques to estimate population size. In: Wildlife Research report. Colorado Division of Wildlife, Fort Collins, pp 47-73

Freddy DJ (2000) Estimating survival rates of elk and developing techniques to estimate population size. In: Wildlife Research report. Colorado Division of Wildlife, Fort Collins, pp 239-258

Freddy DJ (2003) Estimating survival rates of elk and developing techniques to estimate population size. In: Wildlife Research report. Colorado Division of Wildlife, Fort Collins, pp 71-131

Gaillard J-M, Festa-Bianchet M, Yoccoz NG (1998) Population dynamics of larger herbivores: variable recruitment with constant adult survival. Trends Ecol Evol 13:58-63

Gaillard J-M, Festa-Bianchet M, Yoccoz NG, Loison A, Toïgo C (2000) Temporal variation in fitness components and population dynamics of large herbivores. Annu Rev Ecol Syst 31:367-393

Garshelis DL (2000) Delusions in habitat evaluation: measuring use, selection, and importance. In: Boitani L, Fuller TK (eds) Research techniques in animal ecology: controversies and consequences. Columbia University Press, New York, pp 111-164

Guthery FS (2008) A primer on natural resource science. Texas A\&M University Press, College Station

Hayes SG, Leptich DJ, Zager P (2002) Proximate factors affecting male elk hunting mortality in northern Idaho. J Wildl Manage 66:491-499

Hebblewhite M, White CA, Nietvelt CG, McKenzie JA, Hurd TE, Fryxell JM, Bayley SE, Paquet PC (2005) Human activity mediates a trophic cascade caused by wolves. Ecology 86:2135-2144

Hemborg HT (1998) Spanish Peak Field, Las Animas County, Colorado: geologic setting and early development of a coalbed methane reservoir in the central Raton basin. Resource Series 33. Colorado Geological Survey, Denver

Kaplan EL, Meier P (1958) Nonparametric estimation from incomplete observations. J Am Stat Assoc 53:457-481
Kimball JF Jr, Wolfe ML (1974) Population analysis of a northern Utah elk herd. J Wildl Manage 38:161-174

Kimball JF Jr, Wolfe ML (1979) Continuing studies of the demographics of a northern Utah elk population. In: Boyce MS, Hayden-Wing LD (eds) North American elk: ecology, behavior and management. University of Wyoming, Laramie, pp 20-28

Kunkel K, Pletscher DH (1999) Species-specific population dynamics of cervids in a multipredator ecosystem. J Wildl Manage 63:1082-1093

Leptich DJ, Zager P (1991) Road access management effects on elk mortality and population dynamics. In: Christensen AG, Lyon LJ, Lonner TN (eds) Proceedings of a symposium on elk vulnerability. Montana State University, Bozeman, pp 126-131

Lubow BC, Smith BL (2004) Population dynamics of the Jackson elk herd. J Wildl Manage 68:810-829

Lubow BC, Singer FJ, Johnson TL, Bowden DC (2002) Dynamics of interacting elk populations within and adjacent to Rocky Mountain National Park. J Wildl Manage 66:757-775

Lyon LJ, Burcham MG (1998) Tracking elk hunters with the global positioning system. Research paper RMRS-RP-3. Rocky Mountain Research Station, US Forest Service, US Department of Agriculture, Ogden, $6 \mathrm{p}$

McCorquodale SM, Wiseman R, Marcum CL (2003) Survival and harvest vulnerability of elk in the Cascade Range of Washington. J Wildl Manage 67:248-257

McLoughlin PD, Dunford JS, Boutin S (2005) Relating predation mortality to broad-scale habitat selection. J Anim Ecol 74:701-707

McLoughlin PD, Boyce MS, Coulson T, Clutton-Brock T (2006) Lifetime reproductive success and density-dependent multivariable resource selection. Proc R Soc Lond B 273:1449-1454

McShea WJ, Underwood HB, Rappole JH (1997) The science of overabundance: deer ecology and population management. Smithsonian Institution Press, Washington, DC

Michaelis WA, Smith JL, Zahn HM (2005) Estimates of Roosevelt elk survival and annual human-induced losses in the Clearwater GMU. In: Cox M (ed) Proceedings of the 6th western states and provinces deer and elk workshop. Nevada Department of Wildlife, Reno

Millspaugh JJ, Woods RJ, Hunt KE, Raedeke KJ, Brundige GC, Washburn BE, Wasser SK (2001) Fecal glucocorticoid assays and the physiological stress response in elk. Wildl Soc Bull 29:899-907

Nelson LJ, Peek JM (1982) Effect of survival and fecundity on rate of increase of elk. J Wildl Manage 46:535-540

Parker KL, Robbins CT, Hanley TA (1984) Energy expenditures for locomotion by mule deer and elk. J Wildl Manage 48:474-488

Pollock KH, Winterstein SR, Bunck CM, Curtis PD (1989) Survival analysis in telemetry studies: the staggered entry design. J Wildl Manage 53:7-15

Quimby DC, Gaab JE (1957) Mandibular dentition as an age indicator in Rocky Mountain elk. J Wildl Manage 21:435-451

Raedeke KJ, Millspaugh JJ, Clark PE (2002) Population characteristics. In: Toweill DE, Thomas JW (eds) North American elk: ecology and management. Smithsonian Institution Press, Washington, DC, pp 449-491

Rodgers AR, Carr AP, Smith L, Kie JG (2005) HRT: Home range tools for ArcGIS. Ontario Ministry of Natural Resources, Centre for Northern Forest Ecosystem Research, Thunder Bay

Sauer JR, Boyce MS (1983) Density dependence and survival of elk in northwestern Wyoming. J Wildl Manage 47:31-37

Straley JH (1968) Population analysis of ear-tagged elk. Proc Western Assoc State Game Fish Commun 48:152-160

Stussy RJ, Edge WD, O'Neil TA (1994) Survival of resident and translocated female elk in the Cascade Mountains of Oregon. Wildl Soc Bull 22:242-247 
Thompson MJ, Henderson RE (1998) Elk habituation as a credibility challenge for wildlife professionals. Wildl Soc Bull 26:477-483

Unsworth JW, Kuck L, Scott MD, Garton EO (1993) Elk mortality in the clearwater drainage of northcentral Idaho. J Wildl Manage $57: 495-502$

Visual Learning Systems (2008) Feature analyst ${ }^{\circledR} 4.2$ for ArcGIS $^{\circledR}$ reference manual. Visual Learning Systems, Missoula

Vitt A (2007) Trinchera data analysis unit E-33. Game management units 83, 85, 140, 851. Elk management plan. Colorado Division of Wildlife, Pueblo
Winnie J Jr, Creel S (2007) Sex-specific behavioural responses of elk to spatial and temporal variation in the threat of wolf predation. Anim Behav 73:215-225

Wolff JO, Van Horn T (2003) Vigilance and foraging patterns of American elk during the rut in habitats with and without predators. Can J Zool 81:266-271 